\title{
Super soft silicone elastomers with high dielectric permittivity
}

\author{
Madsen, Frederikke Bahrt; Yu, Liyun; Hvilsted, Søren; Skov, Anne Ladegaard
}

Published in:

Proceedings of SPIE: Electroactive Polymer Actuators and Devices (EAPAD) 2015

Link to article, DOI:

$10.1117 / 12.2082929$

Publication date:

2015

Document Version

Publisher's PDF, also known as Version of record

Link back to DTU Orbit

Citation (APA):

Madsen, F. B., Yu, L., Hvilsted, S., \& Skov, A. L. (2015). Super soft silicone elastomers with high dielectric permittivity. In B-C. Yoseph (Ed.), Proceedings of SPIE: Electroactive Polymer Actuators and Devices (EAPAD) 2015 (Vol. 9430). [94301D] SPIE - International Society for Optical Engineering. Proceedings of SPIE - The International Society for Optical Engineering https://doi.org/10.1117/12.2082929

\section{General rights}

Copyright and moral rights for the publications made accessible in the public portal are retained by the authors and/or other copyright owners and it is a condition of accessing publications that users recognise and abide by the legal requirements associated with these rights.

- Users may download and print one copy of any publication from the public portal for the purpose of private study or research.

- You may not further distribute the material or use it for any profit-making activity or commercial gain

- You may freely distribute the URL identifying the publication in the public portal 


\title{
Super soft silicone elastomers with high dielectric permittivity
}

\author{
Frederikke Bahrt Madsen, Liyun Yu, Søren Hvilsted, Anne Ladegaard Skov* \\ Danish Polymer Center, Department of Chemical and Biochemical Engineering, Technical \\ University of Denmark, Building 227, 2800 Kgs. Lyngby, Denmark
}

\begin{abstract}
Dielectric elastomers (DEs) have many favourable properties. The obstacle of high driving voltages, however, limits the commercial viability of the technology at present. Driving voltage can be lowered by decreasing the Young's modulus and increasing the dielectric permittivity of silicone elastomers. A decrease in Young's modulus, however, is often accompanied by the loss of mechanical stability and thereby the lifetime of the DE. New soft elastomer matrices with high dielectric permittivity and low Young's modulus, with no loss of mechanical stability, were prepared by two different approaches using chloropropyl-functional silicone polymers. The first approach was based on synthesised chloropropyl-functional copolymers that were cross-linkable and thereby formed the basis of new silicone networks with high dielectric permittivity (e.g. a $43 \%$ increase). These networks were soft without compromising other important properties of DEs such as viscous and dielectric losses as well as electrical breakdown strength. The second approach was based on the addition of commercially available chloropropyl-functional silicone oil to commercial LSR silicone elastomer. Two-fold increase in permittivity was obtained by this method and the silicone oil decreased the Young's modulus significantly. The viscous losses, however, also increased with increasing content of silicone oil. Cross-linkable chloropropyl-functional copolymers offer a new silicone elastomer matrix that could form the basis of dielectric elastomers of the future, whereas the chloropropyl silicone oil approach is an easy tool for improvement of the properties of existing commercial silicone elastomers.
\end{abstract}

Keywords: Elastomer, silicone, dielectric permittivity, low dielectric loss, low mechanical loss, breakdown *al@kt.dtu.dk; phone + 45 45252825; fax +45 45882258; http://www.dpc.kt.dtu.dk/

\section{INTRODUCTION}

Polydimethylsiloxane (PDMS) elastomers are one of the most commonly used materials for dielectric elastomers (DEs), due to their fast response, high efficiency and low viscous losses, which means that they can be operated at higher frequencies but with lower losses compared to, for example, acrylics or polyurethanes ${ }^{1,2}$.

The commercial viability of DEs is currently limited by a few obstacles including high $\mathrm{kV}$ driving voltages. Higher strains at lower voltages can be obtained by creating elastomer materials with decreased thickness or Young's modulus or increased dielectric permittivity. A thickness reduction has the greatest impact on reducing driving voltage and has the advantage of upholding the losses (dielectric and viscous). Thicknesses as low as $20 \mu \mathrm{m}$ have been reported in current large-scale processing and further reductions could result in the increased importance of inhomogeneities as well as other production related difficulties. However, other production processes inspired by, for example, spin coating could be developed in the future. Much focus has, therefore, during recent years been on increasing the dielectric permittivity of silicone DEs. Increased dielectric permittivity leads to increased elastomer energy density and thereby an increased strain at a given voltage can be obtained $^{3,4}$. Large increases in dielectric permittivity have most often been accomplished through the use of metal oxide fillers creating silicone elastomer composites. Such composite-type systems do, however, have the disadvantage that the Young's modulus of the elastomer is significantly increased and very often the Young's modulus is increased more than the dielectric permittivity and thus no overall improvement is obtained.

Attempts at decreasing the voltage have also been made by decreasing the Young's modulus. These efforts include solvent techniques ${ }^{5}$ and bimodal networks ${ }^{6,7}$. Furthermore, several research studies have attempted to create improved DEs through a combination of decreased Young's modulus and an increased dielectric permittivity, in order to achieve a synergistic impact on lowering the driving voltage. These studies include the use of blends such as PDMS/poly(hexylthiophene) ${ }^{8}$ and PDMS/polyethylene glycol $^{9}$ and a blend of a cyanopropyl-functional PDMS and a PDMS matrix, where the cyano-functional PDMS functioned both as a high dielectric permittivity filler and as a silicone oil that softened the elastomer ${ }^{10}$. All these materials had 
improved electromechanical strain response, since both increased dielectric permittivities and decreased Young's moduli were obtained. The danger of decreasing the Young's modulus of elastomers is, however, that significant changes in several important material properties are often encountered. This includes properties that govern the mechanical stability of the elastomer such as viscous loss, hysteresis and tear strength. Also loss of tension may occur over time. This can compromise the long-term stability and life-time of the DE. Additionally, the above mentioned elastomer materials showed reduced dielectric breakdown strengths, a very important DE parameter, due to increased dielectric losses.

The purpose of this study is to create new types of silicone elastomer matrices with increased dielectric permittivity, low Young's moduli and increased electromechanical strain response without compromising the mechanical integrity of the elastomer or imperative material properties such as dielectric loss, dielectric breakdown strength and viscous loss. The work compares two types of silicone elastomer systems. The first system is based on a new type of chloropropyl-functional siloxane copolymer that is cross-linked together with PDMS polymer chains (DMS-V31). The second system is based on the addition of chloropropyl-functional silicone oil (LMS-152) that is added to a commercial silicone elastomer (ELASTOSIL ${ }^{\circledR}$ LR3043/50). The preparation method of the two systems varies strongly. Where the chloropropyl-functional copolymers require chemical synthesis, the addition of LMS-152 to the commercial elastomers is a simple mixing process. Increased dielectric permittivity of the two systems stems from the high dipole moment of the chloropropylgroups. The bulky nature of the chloropropyl-groups yields a larger free volume around these groups than around the methyl groups on PDMS. This results in a less dense material with a lower Young's modulus. Additionally, for the second system, the use of silicone oil will further soften these networks. The paper will show how the final properties of DEs, such as dielectric and viscous losses, as well as dielectric breakdown strength, are influenced by the two different systems. Furthermore a comparison between cross-linkable polymers and silicone oils on the effect of DE properties will be made.

\section{EXPERIMENTAL}

\subsection{Materials and methods}

Vinyl-terminated PDMS, DMS-V31 ( $\left.\overline{\mathrm{M}}_{W} \approx 28,000 \mathrm{~g} \mathrm{~mol}^{-1}\right)$, a hydride-functional cross-linker, HMS-301, and chloropropyl-functional silicone oil, LMS-152 ( $\left.\bar{M}_{W} \approx 9,000 \mathrm{~g} \mathrm{~mol}^{-1}\right)$, were acquired from Gelest Inc. The platinum cyclovinylmethyl siloxane complex catalyst (511) was purchased from Hanse Chemie, while silicon dioxide amorphous hexamethyldisilazane-treated particles (SIS6962.0) were purchased from Fluorochem. ELASTOSIL ${ }^{\circledR}$ LR3043/50, inhibitor Pt88, solvent Belsil and Belsil resin (TMS 803) were acquired from Wacker Chemie AG. Rutile $\mathrm{TiO}_{2} \mathrm{R} 420$ and $\mathrm{TiO}_{2}$ Hombitec were purchased from Sachtleben and all other chemicals were acquired from Sigma-Aldrich and used as received, unless otherwise stated.

Fourier transform infrared spectroscopy (FTIR) was conducted on a PerkinElmer Spectrum One model 2000 Fourier Transform Infrared apparatus equipped with a universal attenuated total reflection accessory on a $\mathrm{ZnSe} /$ diamond composite. Spectra were recorded in the range of $4000-650 \mathrm{~cm}^{-1}$ with $4 \mathrm{~cm}^{-1}$ resolution and 16 scans. Nuclear magnetic resonance (NMR) spectroscopy $\left({ }^{1} \mathrm{H}\right.$ - and $\left.{ }^{13} \mathrm{C}-\mathrm{NMR}\right)$ experiments were performed on a Bruker $300 \mathrm{MHz}$ spectrometer in $\mathrm{CDCl}_{3}$. Size-exclusion chromatography (SEC) was performed on a Tosoh EcoSEC HLC-8320GPC instrument equipped with RI and UV detectors and SDV Linear S columns from PSS. Samples were run in toluene at $35^{\circ} \mathrm{C}$ at a rate of $1 \mathrm{~mL} \mathrm{~min}^{-1}$, and molar mass characteristics were calculated using WinGPC Unity 7.4.0 software and linear PDMS standards acquired from PSS. Differential scanning calorimetry (DSC) measurements were performed on a DSCQ1000 from TA Instruments. Linear viscoelastic (LVE) data for the films were measured using an ARES-G2 rheometer (TA Instruments) set to a controlled strain mode, with $1 \%$ strain and with frequency sweeps from $100 \mathrm{~Hz}$ to $0.01 \mathrm{~Hz}$ at RT in an ambient atmosphere using a parallel-plate geometry $25 \mathrm{~mm}$ in diameter. Young's moduli were measured using a material tester (Zwick/Roell Zmart.Pro, Zwick GmbH \& Co). The areal dimension of the square sample was $6 \mathrm{~mm} \times 50 \mathrm{~mm}$, and the test specimen was elongated continuously at $10 \mathrm{~mm} \mathrm{~min}^{-1}$ until it reached $15 \%$ strain. The Young's moduli were thereafter calculated from the slopes of the curves at 5\% strain. Stress strain measurements were performed on an in-house-built device, where $2 \mathrm{~cm} \times 2 \mathrm{~cm} \times 73 \mu \mathrm{m}$ to $99 \mu \mathrm{m}$ films were mounted with clamps on a moving stage. The force exerted on the films was then measured as a function of the strain applied by the 
moving stage. Stress was then calculated from the force assuming the incompressibility of the films. Dielectric relaxation spectroscopy (DRS) was performed on a Novocontrol Alpha-A high performance frequency analyser (Novocontrol Technologies $\mathrm{GmbH} \& \mathrm{Co}$ ) operating in the frequency range $10^{-1}-10^{6} \mathrm{~Hz}$ at room temperature. The diameter of the tested $0.5-1 \mathrm{~mm}$ thick samples was $25 \mathrm{~mm}$. Electrical breakdown tests were performed on an in-house-built device based on international standards (IEC 60243-1 (1998) and IEC 60243-2 (2001)), while film thicknesses were measured through microscopy of cross-sectional cuts, and the distance between the spherical electrodes was set accordingly with a micrometre stage and gauge. An indent of less than 5\% of sample thickness was added, to ensure that the spheres were in contact with the sample. The polymer film was slid between the two spherical electrodes (radius of $20 \mathrm{~mm}$ ), and the breakdown was measured at the point of contact by applying a stepwise increasing voltage (50-100 V/step) at a rate of 0.5-1 steps/s. Each sample was subjected to 12 breakdown measurements, and an average of these values was given as the breakdown strength of the sample.

The procedures used for synthesising chloropropyl-functional copolymers have been previously described ${ }^{11}$. Two copolymers were prepared: one copolymer contained chloropropyl-groups with $1200 \mathrm{~g} \mathrm{~mol}^{-1}$ dimethylsiloxane spacer units between each group (ClCo-1), and the other copolymer contained chloropropylgroups with $580 \mathrm{~g} \mathrm{~mol}^{-1}$ dimethylsiloxane spacers between the functional groups (ClCo-2).

General procedure for elastomer synthesis with chloropropyl-functional copolymers:

ClCo-1, ClCo-2 or vinyl-terminated PDMS, DMS-V31 $\left(\bar{M}_{W}=28,000 \mathrm{~g} \mathrm{~mol}^{-1}\right.$, Gelest $)$ or a mixture of these polymers and an 8 -functional cross-linker were mixed with treated silica particles $(25 \mathrm{wt} \%)$, inhibitor ( $1 \mathrm{wt} \%$, Pt88), $\mathrm{TiO}_{2}$ particles (rutile $\mathrm{R} \mathrm{420,} \mathrm{Sachtleben,} \mathrm{if} \mathrm{applied)} \mathrm{and} \mathrm{Belsil} \mathrm{resin} \mathrm{(TMS} \mathrm{803,} \mathrm{if} \mathrm{applied)} \mathrm{and} \mathrm{then}$ treated on a FlackTek Inc. DAC 150.1 FVZ-K SpeedMixerTM. The Pt-catalyst (511) (1.5 ppm) was added thereafter and the mixture was speed-mixed once more. The mixture was then poured into a $1 \mathrm{~mm}$ thick steel mould and furthermore coated as $150 \mu \mathrm{m}$ films on a glass substrate and cured at $80^{\circ} \mathrm{C}$ for 2 hours. The different sample compositions quantities can be found in Table 1 .

Table 1. Compositions and quantities of the prepared samples with chloropropyl-functional copolymers.

\begin{tabular}{|c|c|c|c|c|c|c|c|c|}
\hline \multirow[b]{2}{*}{ Entry } & \multirow[b]{2}{*}{ Composition } & \multicolumn{7}{|c|}{ Quantities } \\
\hline & & ClCo-1 & ClCo-2 & DMS-V31 & $\begin{array}{l}\text { Cross- } \\
\text { linker }\end{array}$ & $\mathrm{SiO}_{2}$ & $\mathrm{TiO}_{2}$ & $\begin{array}{l}\text { Belsil } \\
\text { resin }\end{array}$ \\
\hline DMS-V31 & $\begin{array}{c}\text { Reference sample with } \\
\text { DMS-V31 }\end{array}$ & - & - & $4.00 \mathrm{~g}$ & $0.14 \mathrm{~g}$ & $1.38 \mathrm{~g}$ & - & - \\
\hline CICo-1_50 & $\begin{array}{c}50 \mathrm{~mol} \% \text { DMS-V31 + } \\
50 \mathrm{~mol} \% \text { ClCo-1 }\end{array}$ & $2.00 \mathrm{~g}$ & - & $1.93 \mathrm{~g}$ & $0.13 \mathrm{~g}$ & $1.38 \mathrm{~g}$ & - & - \\
\hline ClCo-1 & Pure ClCo-1 & $4.00 \mathrm{~g}$ & - & - & $0.13 \mathrm{~g}$ & $1.38 \mathrm{~g}$ & - & - \\
\hline Cl-Co2_25 & $\begin{array}{c}75 \text { mol\% DMS-V31 + } \\
25 \text { mol\% ClCo-2 }\end{array}$ & - & $1.00 \mathrm{~g}$ & $2.90 \mathrm{~g}$ & $0.13 \mathrm{~g}$ & $1.38 \mathrm{~g}$ & - & - \\
\hline Cl-Co2_50 & $\begin{array}{c}50 \mathrm{~mol} \% \mathrm{DMS}-\mathrm{V} 31+ \\
50 \mathrm{~mol} \% \mathrm{ClCo}-2\end{array}$ & - & $2 \mathrm{~g}$ & $1.93 \mathrm{~g}$ & $0.13 \mathrm{~g}$ & $1.38 \mathrm{~g}$ & - & - \\
\hline ClCo-2 & Pure ClCo-2 & - & $4.00 \mathrm{~g}$ & - & $0.13 \mathrm{~g}$ & $1.38 \mathrm{~g}$ & - & - \\
\hline $\mathrm{ClCo}-1+\mathrm{TiO}_{2}$ & $\begin{array}{c}\text { ClCo-1 }+30 \mathrm{phr} \\
\mathrm{TiO}_{2}+5 \mathrm{wt} \% \text { belsil resin }\end{array}$ & $4.00 \mathrm{~g}$ & - & - & $0.13 \mathrm{~g}$ & $1.38 \mathrm{~g}$ & $1.65 \mathrm{~g}$ & $0.36 \mathrm{~g}$ \\
\hline $\mathrm{ClCo}-1+\mathrm{TiO}_{2}$ & $\begin{array}{c}\text { ClCo-2 }+30 \mathrm{phr} \\
\mathrm{TiO}_{2}+5 \mathrm{wt} \% \text { belsil resin }\end{array}$ & - & $4.00 \mathrm{~g}$ & - & $0.13 \mathrm{~g}$ & $1.38 \mathrm{~g}$ & $1.65 \mathrm{~g}$ & $0.36 \mathrm{~g}$ \\
\hline
\end{tabular}

General procedure for elastomer synthesis with chloropropyl-functional silicone oil:

An appropriate amount of LMS-152 was mixed with commercial two-component silicone mixture, ELASTOSIL® LR3043/50 (mixed in a 1:1 ratio) (one component was added first), filler materials $\left(\mathrm{TiO}_{2}\right)$, resin (Belsil) and solvent (Belsil) as indicated in Table 2 using Speedmixer. The second elastomer component and inhibitor was then added and the mixture is speedmixed once more. The mixture was then poured into a $1 \mathrm{~mm}$ thick steel mould and furthermore coated as $150 \mu \mathrm{m}$ films on a glass substrate and cured at $115^{\circ} \mathrm{C}$ for 1 hour. The different sample compositions quantities can be found in Table 2. 
Table 2. Compositions and quantities of the samples prepared with chloropropyl-functional silicone oil.

\begin{tabular}{|c|c|c|c|c|c|c|}
\hline \multirow[b]{2}{*}{ Entry } & \multirow[b]{2}{*}{ Composition } & \multicolumn{5}{|c|}{ Quantities } \\
\hline & & $\begin{array}{l}\text { LMS- } \\
152\end{array}$ & LR3043/50A & LR3043/50B & $\mathrm{TiO}_{2}$ & $\begin{array}{l}\text { Belsil } \\
\text { resin }\end{array}$ \\
\hline LR3043/50 & $\begin{array}{c}\text { Reference sample with } \\
\text { LR3043/50 }\end{array}$ & - & $5.00 \mathrm{~g}$ & $5.00 \mathrm{~g}$ & - & - \\
\hline Cl-oil_20phr ${ }^{*}$ & $\begin{array}{c}\text { LR3043/50+20phr }{ }^{*} \text { LMS- } \\
152\end{array}$ & $2.00 \mathrm{~g}$ & $5.00 \mathrm{~g}$ & $5.00 \mathrm{~g}$ & - & - \\
\hline Cl-oil_30phr ${ }^{*}$ & $\begin{array}{c}\text { LR3043/50+ } 30 \mathrm{phr}^{*} \text { LMS- } \\
152\end{array}$ & $3.00 \mathrm{~g}$ & $5.00 \mathrm{~g}$ & $5.00 \mathrm{~g}$ & - & - \\
\hline Cl-oil_40phr ${ }^{*}$ & $\begin{array}{c}\text { LR3043/50+ } 40 \mathrm{phr}^{*} \mathrm{LMS}- \\
152\end{array}$ & $4.00 \mathrm{~g}$ & $5.00 \mathrm{~g}$ & $5.00 \mathrm{~g}$ & - & - \\
\hline Cl-oil_100phr ${ }^{*}$ & $\begin{array}{c}\text { LR3043/50+ } 100 \mathrm{phr}^{*} \\
\text { LMS-152 }\end{array}$ & $10.0 \mathrm{~g}$ & $5.00 \mathrm{~g}$ & $5.00 \mathrm{~g}$ & - & - \\
\hline Cl-oil_100phr* +belsil & $\begin{array}{c}\text { LR3043/50+ } 100 \mathrm{phr}^{*} \\
\text { LMS-152+5wt\% belsil } \\
\text { resin }\end{array}$ & $10.0 \mathrm{~g}$ & $5.00 \mathrm{~g}$ & $5.00 \mathrm{~g}$ & - & $1.00 \mathrm{~g}$ \\
\hline Cl-oil_30phr* $+\mathrm{TiO}_{2}(1)$ & $\begin{array}{l}\text { LR3043/50+ } 30 \text { phr }^{*} \text { LMS- } \\
152+5 \mathrm{wt} \% \text { belsil } \\
\text { resin+30phr }{ }^{*} \mathrm{TiO}_{2} \text { (R 420) }\end{array}$ & $1.50 \mathrm{~g}$ & $2.50 \mathrm{~g}$ & $2.50 \mathrm{~g}$ & $1.50 \mathrm{~g}$ & $0.40 \mathrm{~g}$ \\
\hline Cl-oil_30phr ${ }^{*}+\mathrm{TiO}_{2}(2)$ & $\begin{array}{c}\text { LR3043/50+ } 30 \text { phr }^{*} \text { LMS- } \\
\text { 152+5wt } \% \text { belsil } \\
\text { resin+30phr }{ }^{*} \mathrm{TiO}_{2} \\
(\text { Hombitec) }\end{array}$ & $1.80 \mathrm{~g}$ & 3.00 & $3.00 \mathrm{~g}$ & $1.80 \mathrm{~g}$ & $0.48 \mathrm{~g}$ \\
\hline
\end{tabular}

\section{RESULTS AND DISCUSSION}

Silicone elastomers with high dielectric permittivity and low Young's moduli were prepared using chloropropyl-functional siloxane polymers. Elastomer systems were prepared using two different approaches. The first approach was based on allyl-terminated chloropropyl-functional copolymers which were prepared according to a previously described procedure ${ }^{11-13}$. The allyl-groups on the copolymers allowed for platinum catalysed addition reactions with hydride-functional cross-linkers and thereby incorporation of the copolymers into the silicone network. The second approach was based on the addition of chloropropyl-functional silicone oil to a commercial silicone elastomer. The two different approaches allow for a comparison between crosslinked and non-cross-linked chloropropyl siloxane polymers and their influence on the properties of DEs.

\section{1 $1^{\text {st }}$ approach: Allyl-terminated chloropropyl-functional copolymers}

The allyl-terminated chloropropyl-functional copolymers were prepared through the tris(pentafluorophenyl)borane-catalysed Piers-Rubinsztajn reaction of the commercially available starting materials chloropropylmethyldimethoxysilane and hydride-terminated dimethylsiloxane pre-polymers. Two different dimethylsiloxane pre-polymer chain lengths constituted the spacer units between the chloropropylmethylsiloxane units as shown in Scheme 1. 


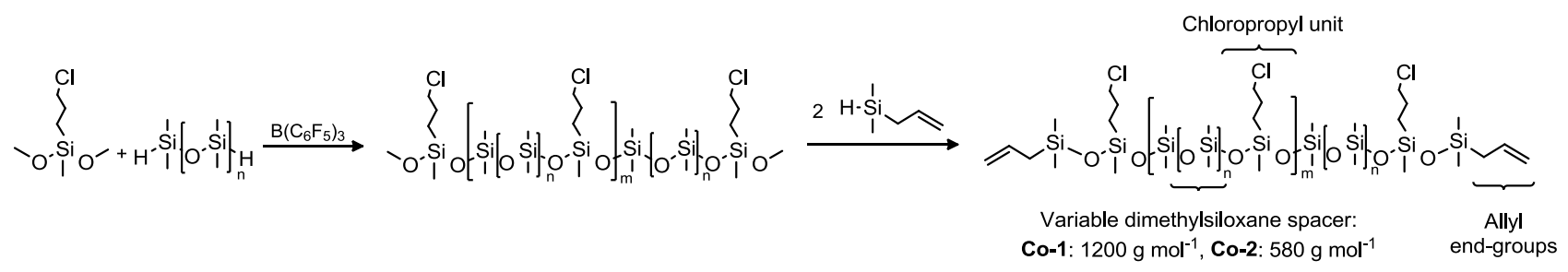

Scheme 1. Synthetic route for allyl-terminated chloropropyl-functional copolymers.

The chloropropyl-functional copolymers were end-functionalised with allyldimethylsilane, and the allyl-groups allows for addition reactions with hydride-terminated cross-linkers - and thereby the formation of silicone elastomer networks.

Two different chloropropyl-functional copolymers were prepared. The first copolymer contained chloropropylgroups with $1200 \mathrm{~g} \mathrm{~mol}^{-1}$ dimethylsiloxane spacer units between each group (CICo-1), and the other copolymer contained chloropropyl-groups with $580 \mathrm{~g} \mathrm{~mol}^{-1}$ dimethylsiloxane spacers between the functional groups (ClCo-2). Thus, at comparable copolymer chain lengths CICo-2 contains approximately double the number of chloropropyl-groups than ClCo-1.

During the synthesis of the two copolymers the target was to obtain identical molecular weights of the two copolymers. This allows for easy comparison of their elastomer properties. The obtained molecular weights of CICo-1 and CICo-2 were analysed by size exclusion chromatography (SEC) and molar mass characteristics were calculated from linear polydimethylsiloxane standards. Both, CICo-1 and CICo-2 were found to have molecular weights of $\bar{M}_{W} \approx 29,000 \mathrm{~g} \mathrm{~mol}^{-1}$, which is a suitable molecular weight for silicone elastomers, since good mechanical properties are obtained when using polymers between 20,000 and $30,000 \mathrm{~g} \mathrm{~mol}^{-1}$. ${ }^{14}$ Molecular weights of $\bar{M}_{W} \approx 29,000 \mathrm{~g} \mathrm{~mol}^{-1}$ mean that ClCo-1 and ClCo-2 contain approximately 20 and 40 chloropropyl units, respectively.

The chloropropyl-functional copolymers, ClCo-1 and CICo-2, were transformed into silicone elastomers by reaction with 8-functional hydride cross-linkers (HMS-301) using 25wt\% surface-treated silica particles as reinforcement. Samples were prepared with pure copolymer or as mixtures with a $28,000 \mathrm{~g} \mathrm{~mol}^{-1}$ vinylterminated PDMS (DMS-V31). An overview of the prepared samples is shown in Table 3. A reference sample made from PDMS (DMS-V31), using similar reaction conditions (same cross-linker, particle, and catalyst concentration), was also prepared. Furthermore, elastomer samples with ClCo-1 or ClCo-2 and $\mathrm{TiO}_{2}$ particles and reinforcing Belsil resin was also prepared (see Table 1) as $\mathrm{TiO}_{2}$ may increase dielectric permittivity even further.

Table 3. Overview of the prepared elastomer samples with ClCo-1 and ClCo-2.

\begin{tabular}{|ccc|}
\hline Entry & $\begin{array}{c}\text { Content of copolymer } \\
\text { [mol\%] }\end{array}$ & $\begin{array}{c}\text { Content of DMS-V31 } \\
\text { [mol\%] }\end{array}$ \\
DMS-V31 & 0 & 100 \\
ClCo-1_50 & 50 & 50 \\
ClCo-1 & 100 & 0 \\
ClCo-2_25 & 25 & 75 \\
ClCo-2_50 & 50 & 50 \\
ClCo-2 & 100 & 0 \\
ClCo-1+TiO & 100 & 0 \\
ClCo-2+TiO & 100 & 0 \\
\hline
\end{tabular}

The effect of chloropropyl-groups in silicone elastomers on the thermal transition behaviour was determined by DSC. The reference elastomer made from pure PDMS DMS-V31 had clear melting and crystallisation temperatures at $T \mathrm{~m}=-46^{\circ} \mathrm{C}$ and $T \mathrm{c}=-75^{\circ} \mathrm{C}$, respectively. The elastomers prepared with ClCo-1 and ClCo-2, had no clear $T \mathrm{~m}$ or $T \mathrm{c}$, which means that no crystalline regions were present in these elastomers. This is likely 
due to the chloropropyl side-chains, which prevent alignment of linear polymer segments necessary for crystallisation. This is also an indication of the fact that the bulky nature of the chloropropyl-groups compared to methyl-groups on PDMS yields softer elastomer materials.

In order to elucidate the viscoelastic properties of the elastomers prepared with $\mathbf{C l C o - 1}$ and $\mathbf{C l C o - 2}$, the shear storage moduli and shear loss moduli were measured using linear shear rheology. The results are shown in Figure 1 and furthermore, the measured shear storage moduli (G') and losses ( $\tan \delta$ ) at $1 \mathrm{~Hz}$ are summarised in Table 4.

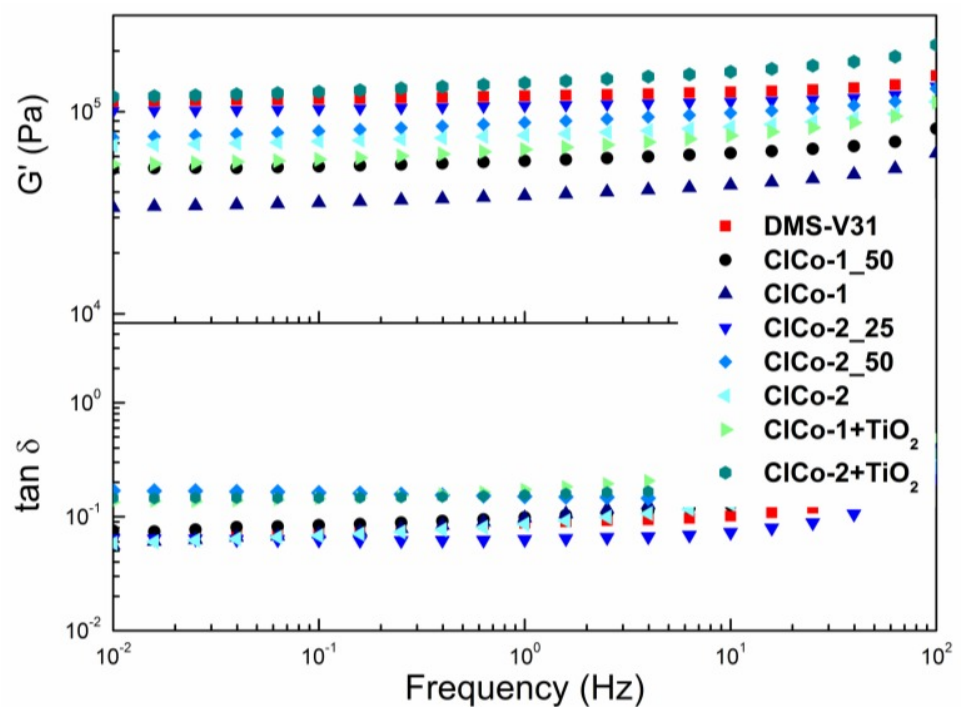

Figure 1. Storage moduli (G') and loss ( $\tan \delta$ ) as functions of frequency for elastomers prepared with chloropropylfunctional copolymers.

From Figure 1 and Table 4 it is seen that all elastomers prepared with chloropropyl-functional siloxane copolymers have lower moduli than the PDMS reference based on DMS-V31 with one exception - ClCo$\mathbf{2}+\mathbf{T i O}_{2}$ which is slightly stiffer due to the addition of both $\mathrm{TiO}_{2}$ and reinforcing resin. Furthermore, the viscous losses, $\tan \delta$, are maintained at the same low level as the PDMS reference for all elastomers, expect for CICo2_50 and the samples with $\mathrm{TiO}_{2}$ where $\tan \delta$ has increased only slightly. This verifies that the mechanical integrity of the elastomers prepared with chloropropyl-functional copolymers has not been lost or compromised, even though the elastomers are significantly softer than the PDMS reference and silicone elastomers in general. The Young's moduli and stress-strain behaviour were determined by tensile tests. The resulting stress-strain curves are shown in Figure 2 and the Young's moduli, which were calculated as the slopes of stress-strain curves at $5 \%$ strain, are furthermore summarised in Table 4. 


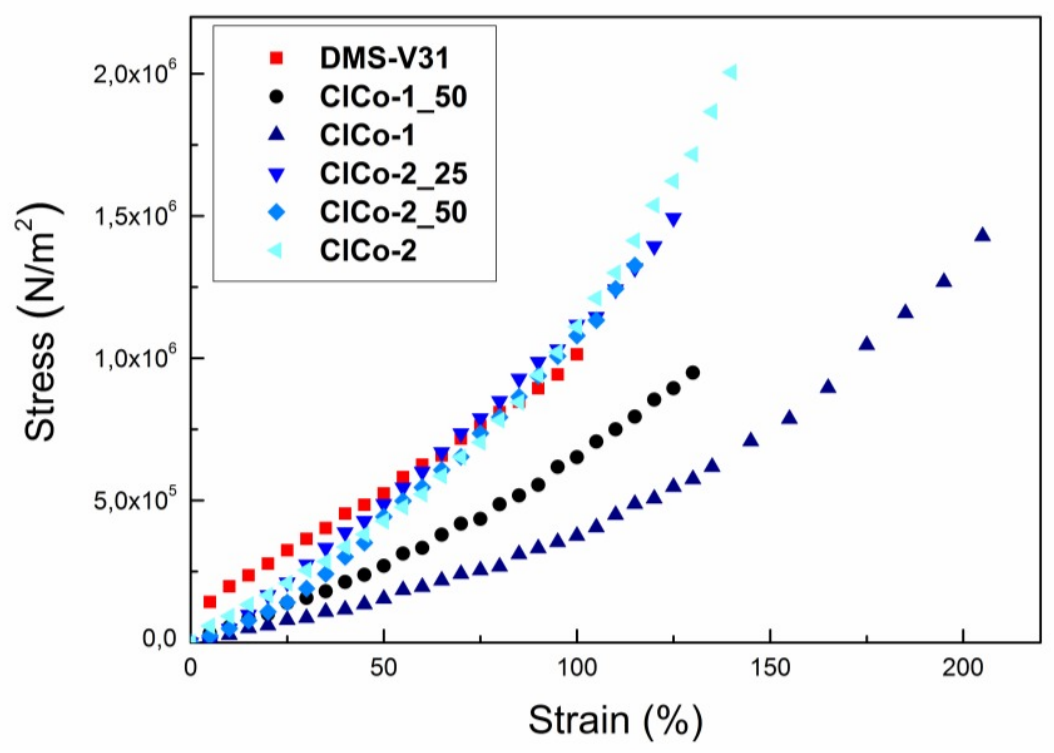

Figure 2. Stress-strain curves for elastomers prepared with chloropropyl-functional copolymers.

The stress-strain curves illustrate the softening effect that the chloropropyl-functional copolymers have on the elastomers. ClCo-1, for instance, has significantly reduced elastic modulus and increased strain at breakage compared to those samples containing copolymers mixed with the PDMS reference polymer DMS-V31 and the pure reference film. As a comparison to commercial elastomers, which usually have Young's moduli in the order of 1-2 MPa, the Young's modulus of ClCo-1 of $\sim 0.1 \mathrm{MPa}$ in itself facilitates 10 times more actuation at low strains. Furthermore, the elastomer samples prepared with ClCo-2, which has the highest content of chloropropyl segments, are all stiffer than the elastomer samples prepared with ClCo-1. This could also be seen from the rheology data shown in Figure 1. Moreover, the shapes of the stress-strain curves for chloropropylfunctional elastomers indicate that they are very favourable for electromechanical actuation without prestretching. Traditional non-linear silicone elastomers tend to strain-soften at higher strains, which makes prestretch favourable ${ }^{2},{ }^{15}$. The chloropropyl-functional elastomers, however, are soft from zero strain and harden gradually when further strain is applied. This strain-hardening effect could suppress the electromechanical instability (EMI) phenomenon, which can be explained as follows: as the voltage over the DE is increased, the elastomer thins down. This increases the electrical field at the given voltage and the elastomer thins down even further. If the elastomer is strain-softening, this positive feedback may cause direct dielectric breakdown ${ }^{16-19}$.

The dielectric properties of the chloropropyl-functional elastomers were determined through dielectric spectroscopy and the results are presented in Figure 3 and summarized in Table 4. 


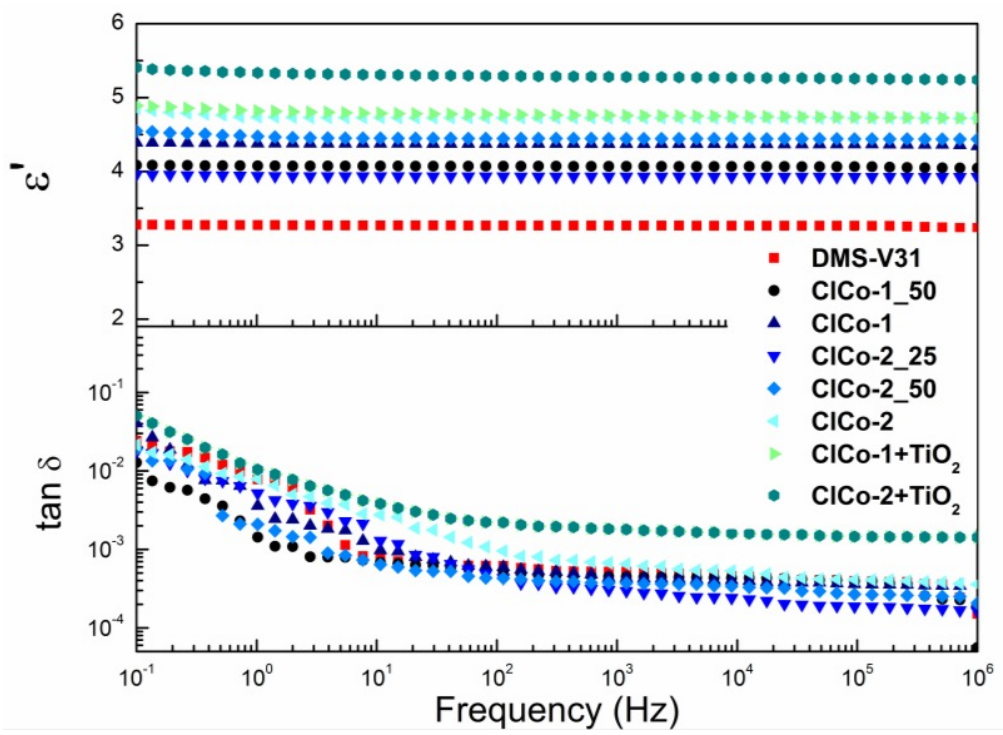

Figure 3. Dielectric permittivity $\left(\varepsilon^{\prime}\right)$ and loss tangent $(\tan \delta)$ as functions of frequency for elastomers prepared with chloropropyl-functional copolymers.

The elastomers prepared with chloropropyl-functional copolymers all have increased dielectric permittivity compared to the PDMS reference, which has $\varepsilon^{\prime}=3.3$. The dielectric permittivity is furthermore - as expected seen to increase with increasing content of chloropropyl-groups in the elastomers reaching as high as $\varepsilon^{\prime}=4.7$ for the elastomer prepared with ClCo-2, which corresponds to an increase of $43 \%$ compared to the PDMS reference. Furthermore, the addition of $\mathrm{TiO}_{2}$ increases permittivity even further to 4.8 for $\mathbf{C l C o - 1}+\mathbf{T i O}_{2}$ and 5.3

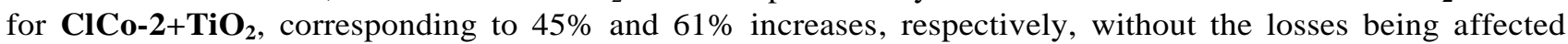
significantly. The dielectric permittivity is seen to remain constant in the entire measured frequency range, which indicates that no Maxwell polarisation ${ }^{20}$ processes are taking place. This is further elucidated from the loss (shown as $\tan \delta$ ) with no indication of characteristic relaxation unless at the lowest frequencies (electrode polarization) and remaining as low as the PDMS reference for all prepared chloropropyl-functional elastomers. The conductivities as function of frequency for elastomers prepared with chloropropyl-functional copolymers are shown in Figure 4.

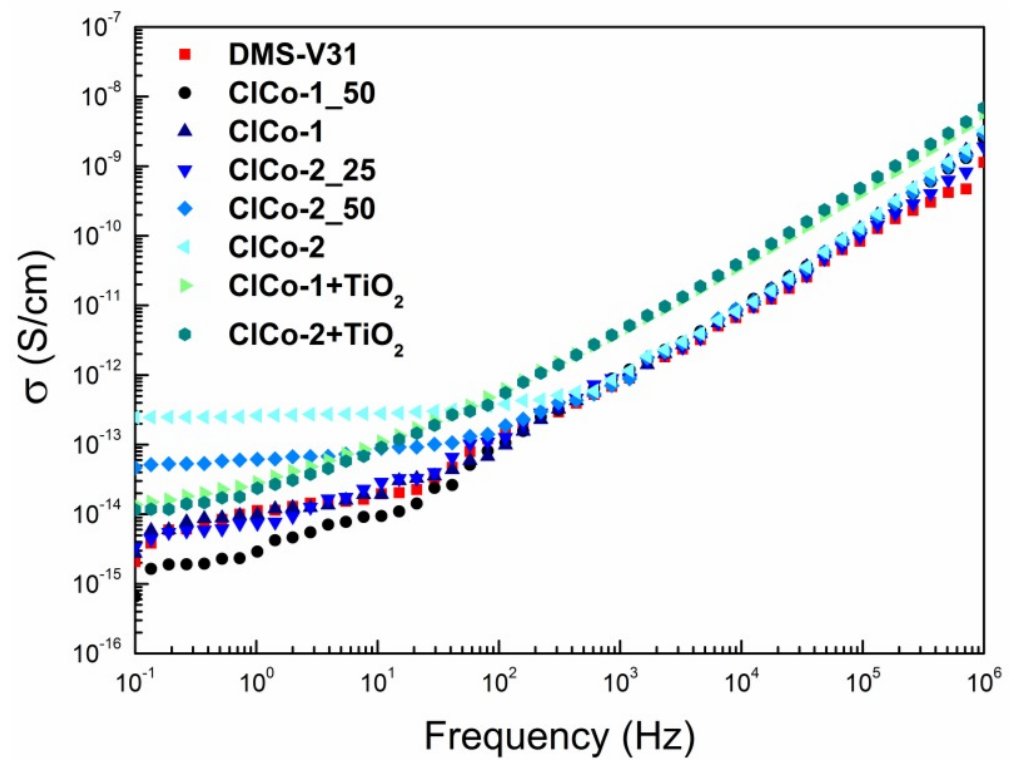

Figure 4. Conductivity as function of frequency for elastomers prepared with chloropropyl-functional copolymers. 
From Figure 4 it can be seen that elastomers with the highest content of chloropropyl-groups (ClCo-2_50 and CICo-2) have slightly increased conductivity compared to the PDMS reference. The values of the conductivity, however, remain very low. All other elastomers prepared with chloropropyl-functional copolymers show no increased conductivity, and in fact the ClCo-1_50 has the lowest conductivity of all samples $\left(2 * 10^{-15} \mathrm{~S} / \mathrm{cm}\right)$.

The dielectric breakdowns strengths, $E_{\mathrm{B}}$, for the elastomers prepared with chloropropyl-functional copolymers are presented in Table 4.

Table 4. Dielectric permittivity $\left(\varepsilon^{\prime}\right)$ and loss tangent $(\tan \delta)$ at $100 \mathrm{~Hz}$, breakdown strengths $\left(E_{\mathrm{B}}\right)$, storage moduli $\left(\mathrm{G}^{\prime}\right)$ and loss $(\tan \delta)$, Young's moduli as well as the figure of merit for elastomers with chloropropyl-functional copolymers and the PDMS reference, DMS-V31.

\begin{tabular}{|c|c|c|c|c|c|c|c|}
\hline \multirow[b]{2}{*}{$\begin{array}{c}\text { Film with } \\
\text { entry }\end{array}$} & \multicolumn{2}{|c|}{$\begin{array}{c}\text { Dielectric } \\
\text { spectroscopy }\end{array}$} & \multirow{2}{*}{$\begin{array}{c}\text { Electrical } \\
\text { breakdown } \\
\boldsymbol{E}_{\mathrm{B}} \\
{[\mathrm{V} / \mu \mathrm{m}]}\end{array}$} & \multicolumn{2}{|c|}{ Rheology } & \multirow{2}{*}{$\begin{array}{c}\text { Tensile } \\
\text { tests } \\
\text { Y @ 5\% } \\
\text { strain } \\
\text { [MPa] }\end{array}$} & \multirow{2}{*}{$\begin{array}{c}\begin{array}{c}\text { Figure of } \\
\text { merit }\end{array} \\
F_{o m} / F_{o m_{-} r e f}\end{array}$} \\
\hline & $\begin{array}{c}\varepsilon^{\prime} \\
@ \mathbf{1 0 0 H z}\end{array}$ & $\begin{array}{c}\tan \delta \\
@ 100 \mathrm{~Hz}\end{array}$ & & $\begin{array}{c}\text { G' } \\
@ 1 \mathbf{H z} \\
{[\mathbf{k P a}]}\end{array}$ & $\begin{array}{l}\tan \delta \\
@ 1 H z\end{array}$ & & \\
\hline DMS-V31 & 3.3 & $6.2 * 10^{-4}$ & 81.6 & 119.7 & 0.088 & 3.8 & 1.0 \\
\hline Co-1_50 & 4.1 & $5.3 * 10^{-4}$ & 84.3 & 57.2 & 0.098 & 0.95 & 5.3 \\
\hline Co-1 & 4.4 & $5.9 * 10^{-4}$ & 73.9 & 38.4 & 0.097 & 0.40 & 10.4 \\
\hline Co-2_25 & 3.9 & $4.3 * 10^{-4}$ & 101.2 & 107.1 & 0.063 & 2.8 & 2.5 \\
\hline Co-2_50 & 4.4 & $4.3 * 10^{-4}$ & 99.8 & 88.3 & 0.150 & 1.5 & 5.1 \\
\hline Co-2 & 4.7 & $9.5 * 10^{-4}$ & 94.4 & 76.4 & 0.085 & 1.0 & 7.2 \\
\hline $\mathrm{ClCo}-1+\mathrm{TiO}_{2}$ & 4.8 & $22 * 10^{-4}$ & 73.2 & 64.9 & 0.170 & - & 2.2 \\
\hline $\mathrm{ClCo}-2+\mathrm{TiO}_{2}$ & 5.3 & $22 * 10^{-4}$ & 85.6 & 138.9 & 0.160 & - & 1.5 \\
\hline
\end{tabular}

As seen from the results in Table 4 the dielectric breakdown strength is increased or maintained at roughly the same level for the chloropropyl-functional elastomers compared to the PDMS reference, which suggests that the new chloropropyl-functional elastomers as matrices for DEs do not compromise the dielectric breakdown strength. In fact the elastomers based on the ClCo-2 copolymer possesses higher dielectric breakdown strength than the reference.

The figure of merit, $F_{\text {om }}$, is a universal expression, defined by Sommer-Larsen and Larsen ${ }^{21}$, which through a single parameter can be used to evaluate the performance of a DE at a constant potential. The figure of merit depends on the dielectric constant, dielectric breakdown strength and the Young's modulus ( $\left.Y=3 G^{\prime}\right)$ of the elastomer and is defined as:

$$
F_{o m}=\frac{3 \varepsilon^{\prime} \times E_{B}^{2}}{Y}=\frac{\varepsilon^{\prime} \times E_{B}^{2}}{G^{\prime}}
$$

The overall DE properties of the elastomers with the chloropropyl-functional copolymers can be compared to the properties of the PDMS reference by calculating the $F_{o m}$ of a given elastomer sample relative to the $F_{o m}$ of the reference material $\left(F_{\text {om }} / F_{\text {om_ref }}\right)$ and the results are shown in Table 4 . It is evident from the figure of merit calculations that all elastomer samples prepared with chloropropyl-functional copolymers show improved overall properties compared to the PDMS reference. The largest increase in the figure of merit is obtained for films with pure chloropropyl-functional copolymers (CICo-1 and ClCo-2), where the figure of merit is increased 10 and 7 times, respectively, compared to the PDMS reference film with DMS-V31. For CICo-1 the high figure of merit is obtained mainly due to a combination of high dielectric permittivity and very low Young's modulus. For ClCo-2 the high figure of merit is obtained due to high dielectric permittivity and high dielectric breakdown strength as well as the relatively low Young's modulus. 


\section{$3.22^{\text {nd }}$ approach: chloropropyl-functional silicone oil as additive to commercial silicone elastomer}

Due to the favourable properties of the copolymer based elastomers in the first approach a more simple approach was attempted, namely, mixing of commercial elastomer with chloropropyl-functional silicone oil (LMS-152 $\left(\bar{M}_{W} \approx 9,000 \mathrm{~g} \mathrm{~mol}^{-1}\right)$, which is depicted in Figure 5).

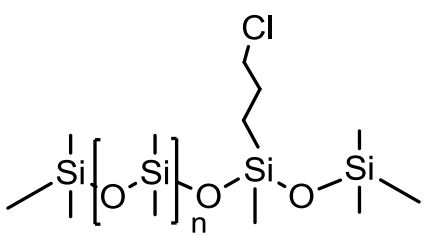

Figure 5. Structure of LMS-152 chloropropyl-functional silicone oil.

The chloropropyl-functional silicone oil was mixed into commercially available elastomer system ELASTOSIL $®$ LR3043/50, a two-part liquid silicone rubber (LSR) where the two parts (A and B) are mixed in a 1:1 ratio. A sample containing high concentration of silicone oil (100 parts per hundred rubber (phr)) was furthermore reinforced with $5 \mathrm{wt} \%$ belsil resin. Furthermore, samples containing $30 \mathrm{phr}$ silicone oil were mixed with two types of $\mathrm{TiO}_{2}$ particles ( $\mathrm{R} 420$ or Hombitec). A reference sample consisting of pure ELASTOSIL® LR3043/50 was also prepared. All sample compositions can be seen in Table 2.

The viscoelastic properties of the samples prepared with chloropropyl-functional silicone oil were measured by linear shear rheology and the resulting shear storage moduli (G') and losses (tan $\delta$ ) are shown in Figure 6 and furthermore summarized in Table 5.

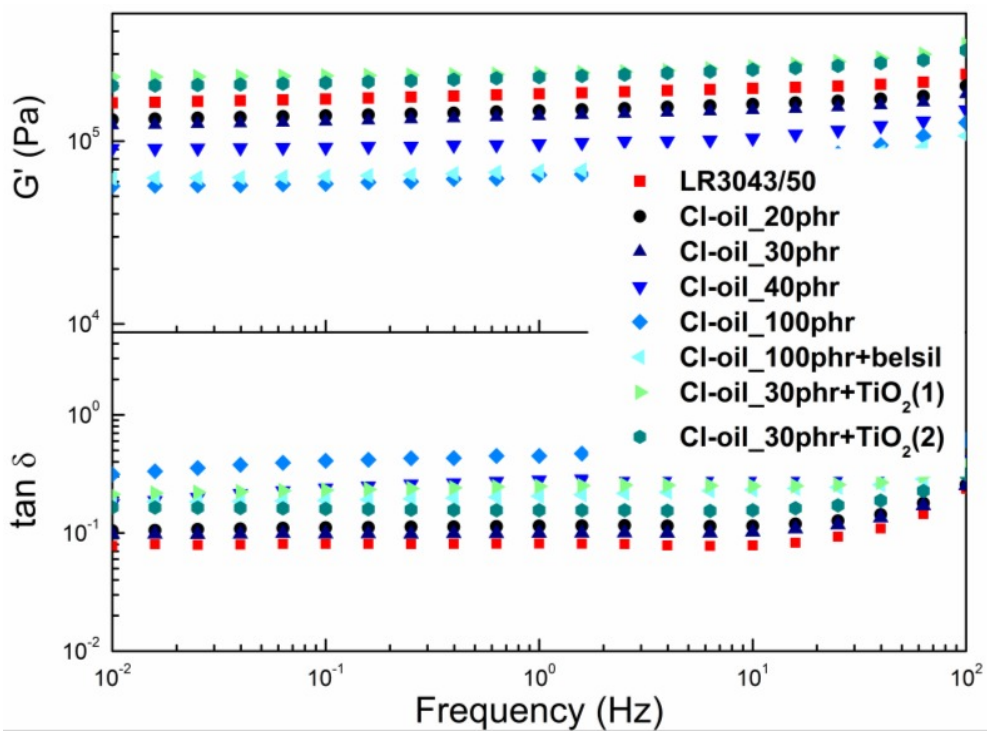

Figure 6. Storage moduli (G') and loss ( $\tan \delta)$ as functions of frequency for elastomers prepared with chloropropylfunctional silicone oil.

It can be seen in Figure 6 and Table 5 that the storage moduli are of the order of factor 2 higher than elastomers from the first approach. This is expected since the LR3043/50 is a very strong elastomer with Young's modulus around $2 \mathrm{MPa}$ due to a high degree of reinforcing fillers ${ }^{22}$. The elastomers become increasingly softer with increasing amount of LMS-152 silicone oil, as expected. Moreover, the losses, $\tan \delta$, increases with increasing amount of silicone oil, and are higher than for approach 1, which is also expected due to the larger amounts of non-bonded structures in the networks, which gives rise to viscoelastic relaxation. Moreover, it can be seen that 
the addition of $5 \mathrm{wt} \%$ belsil resin to the very soft $100 \mathrm{phr}$ sample reinforces the network slightly whereas the losses have improved two-fold indicating that the resin immobilises some of the silicone oil. This gives an overall improved network. It can furthermore be seen that the addition of $\mathrm{TiO}_{2}$ particles to the $30 \mathrm{phr}$ samples increases the moduli a great deal and the films have become significantly stiffer - irrespective of the type of $\mathrm{TiO}_{2}$ used. Furthermore, the losses have increased slightly with the addition of the $\mathrm{TiO}_{2}$ particles but remain low for the Hombitec $\mathrm{TiO}_{2}$. The Young's moduli which are shown in Table 5 also illustrate that the elastomers are softened by the increasing addition of silicone oil and that $\mathrm{TiO}_{2}$ particles significantly stiffen the network.

The dielectric spectra of the elastomers mixed chloropropyl-functional silicone oil are presented in Figure 7 and summarized in Table 5.

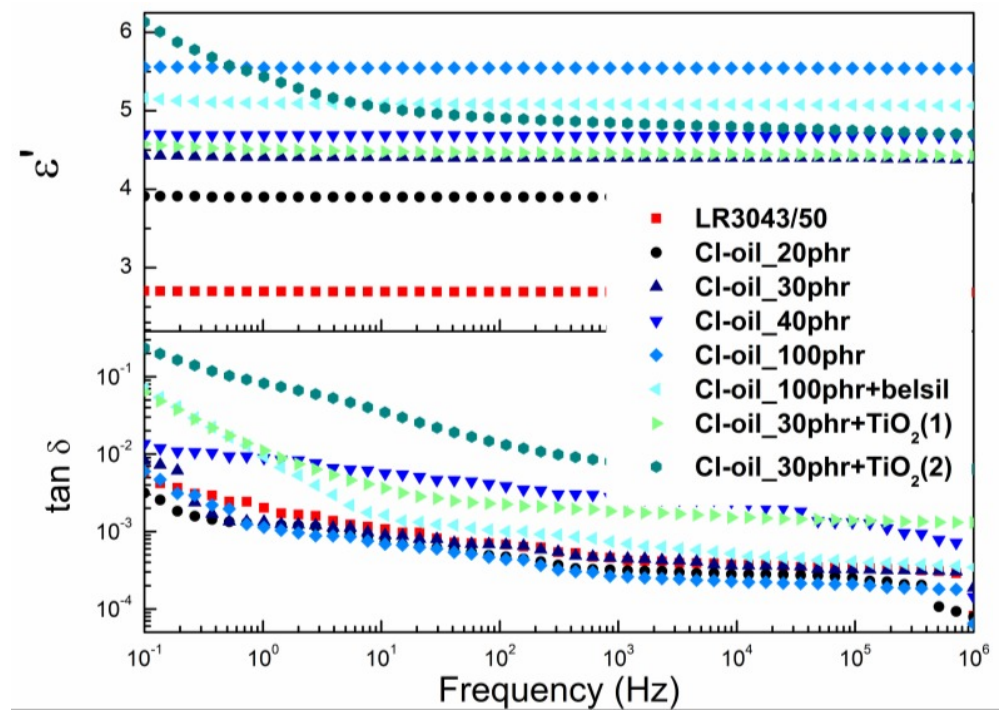

Figure 7. Dielectric permittivity $\left(\varepsilon^{\prime}\right)$ and loss tangent $(\tan \delta)$ as functions of frequency for elastomers prepared with chloropropyl-functional silicone oil.

The dielectric permittivity increases with increasing content of chloropropyl-functional silicone oil reaching $\varepsilon^{\prime}=5.5$ for the elastomers with $100 \mathrm{phr}$ LMS-152. This corresponds to an increase of 104\% compared to the pure LR3043/50 elastomers for which $\varepsilon^{\prime}=2.7$. By addition of belsil resin to the elastomer with $100 \mathrm{phr}$ silicone oil, the dielectric permittivity drops slightly to $\varepsilon^{\prime}=5.1$ due to the diluting effect of the resin, which does not contribute with a large dielectric permittivity. The addition of $\mathrm{TiO}_{2}$ to the elastomer with $30 \mathrm{phr}$ silicone oil increases the permittivity somewhat. $\mathrm{R} 420 \mathrm{TiO}_{2}$ increases the permittivity from $\varepsilon^{\prime}=4.4$ to $\varepsilon^{\prime}=4.5$ whereas Hombitec $\mathrm{TiO}_{2}$ increases the permittivity to $\varepsilon^{\prime}=4.9$. The dielectric losses remain low for most of the samples expect for those containing $\mathrm{TiO}_{2}$. Particularly the sample containing Hombitec $\mathrm{TiO}_{2}$ show increased dielectric loss especially at low frequencies.

The results of the dielectric breakdown strength measurements are shown in Table 5. The addition of low amounts of chloropropyl silicone oil to the commercial silicone elastomers is seen to increase the breakdown strength. Thereafter, the breakdown strength decrease with increasing content of LMS-152. This is probably due to decreased stiffness of the elastomers which has a large impact on the breakdown strength ${ }^{23}$.

The conductivities as function of frequency for elastomers prepared with chloropropyl-functional silicone oil are shown in Figure 8. 


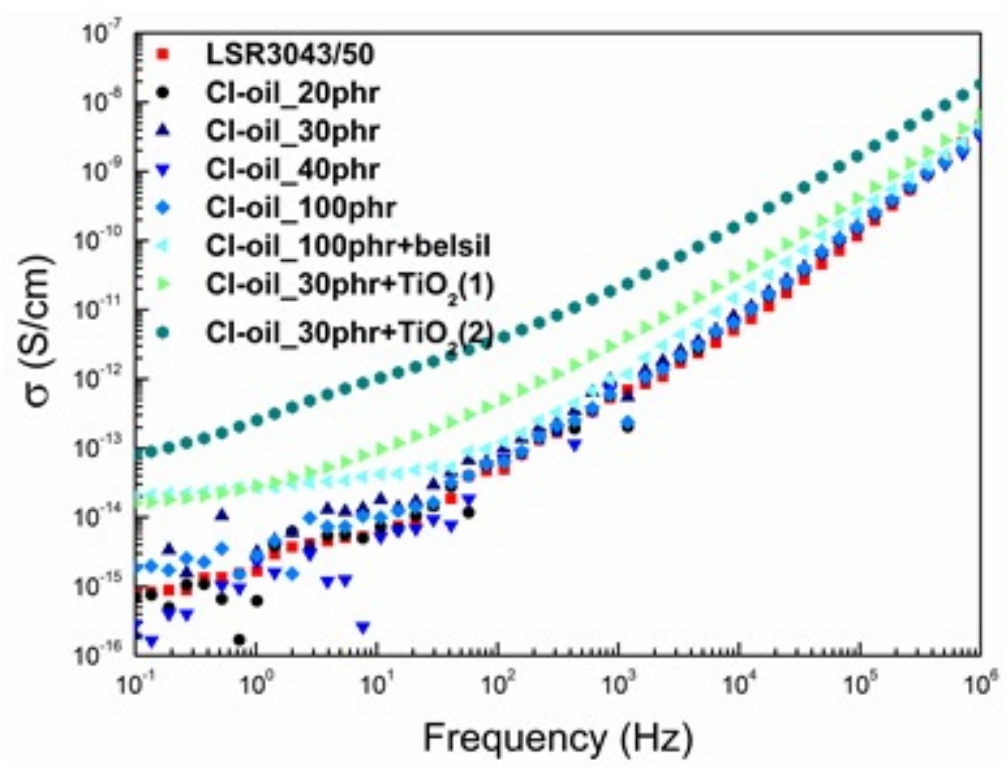

Figure 8. Conductivity as function of frequency for elastomers prepared with chloropropyl-functional silicone oil.

It can be seen in Figure 8 that the conductivities remain low for all samples prepared with chloropropyl-functional silicone oil. The conductivity is, however, slightly increased for the elastomer with $\mathrm{Hombitec}_{\mathrm{TiO}}$.

Table 5. Dielectric permittivity $\left(\varepsilon^{\prime}\right)$ and loss tangent $(\tan \delta)$ at $100 \mathrm{~Hz}$, breakdown strengths $\left(E_{\mathrm{B}}\right)$, storage moduli $\left(\mathrm{G}^{\prime}\right)$ and loss $(\tan \delta)$, Young's moduli as well as the figure of merit for elastomers with chloropropyl-functional silicone oil as an additive to ELASTOSIL LR3043/50.

\begin{tabular}{|c|c|c|c|c|c|c|c|}
\hline \multirow[b]{2}{*}{ Film with entry } & \multicolumn{2}{|c|}{$\begin{array}{c}\text { Dielectric } \\
\text { spectroscopy }\end{array}$} & \multirow{2}{*}{$\begin{array}{c}\begin{array}{c}\text { Electrical } \\
\text { breakdown }\end{array} \\
E_{\mathrm{B}} \\
{[\mathrm{V} / \mu \mathrm{m}]}\end{array}$} & \multicolumn{2}{|c|}{ Rheology } & \multirow{2}{*}{$\begin{array}{c}\text { Tensile } \\
\text { tests } \\
\text { Y @ 5\% } \\
\text { strain } \\
\text { [MPa] }\end{array}$} & \multirow{2}{*}{$\begin{array}{c}\begin{array}{c}\text { Figure of } \\
\text { merit }\end{array} \\
F_{o m} / F_{o m_{-} r e f}\end{array}$} \\
\hline & $\begin{array}{c}\varepsilon^{\prime} \\
@ 100 \mathrm{~Hz}\end{array}$ & $\begin{array}{c}\tan \delta \\
@ 100 H z\end{array}$ & & $\begin{array}{c}\text { G' } \\
@ 1 \mathbf{H z} \\
{[\mathbf{k P a}]}\end{array}$ & $\begin{array}{l}\tan \delta \\
@ 1 H z\end{array}$ & & \\
\hline LR3043/50 & 2.7 & $6.8 * 10^{-4}$ & 121.0 & 181.5 & 0.081 & 2.00 & 1.0 \\
\hline Cl-oil_20phr* & 3.9 & $4.7 * 10^{-4}$ & 151.0 & 146.7 & 0.114 & 1.80 & 2.5 \\
\hline Cl-oil_30phr* & 4.4 & $6.7 * 10^{-4}$ & 129.9 & 137.5 & 0.100 & 1.35 & 2.8 \\
\hline Cl-oil_40phr* & 4.7 & $38 * 10^{-4}$ & 118.3 & 96.8 & 0.280 & 1.35 & 2.5 \\
\hline Cl-oil_100phr* & 5.5 & $4.4 * 10^{-4}$ & 88.2 & 65.4 & 0.449 & 0.75 & 2.9 \\
\hline Cl-oil_100 phr" + belsil & 5.1 & $10 * 10^{-4}$ & 81.9 & 68.5 & 0.205 & - & 2.3 \\
\hline Cl-oil_30phr ${ }^{*}+\mathrm{TiO}_{2}(1)$ & 4.5 & $22 * 10^{-4}$ & 109.2 & 234.7 & 0.248 & - & 1.0 \\
\hline Cl-oil_30phr ${ }^{*}+\mathrm{TiO}_{2}(2)$ & 4.9 & $131 * 10^{-4}$ & 125.1 & 223.9 & 0.156 & 3.10 & 1.3 \\
\hline
\end{tabular}

The figure of merit calculations which are shown in Table 5 indicate the combined effect of the chloropropylfunctional silicone oil on the properties of commercial elastomers ELASTOSIL LR3043/50. It can be seen that all samples with chloropropyl-functional silicone oil show improved overall properties compared to the pure silicone elastomer. The highest figures of merits are obtained for elastomers with reinforcing resins or $\mathrm{TiO}_{2}$ as these elastomers are stiffer than the elastomers where only silicone oil has been added. Overall, the addition of chloropropyl silicone oil is an easy method for improvement of commercial silicone elastomers.

It is obvious that the two approaches yield very different elastomers. Approach 1 results in very soft elastomers, which mainly performs better than traditional elastomers due to their very soft nature. Approach 2 yields favourable elastomers due to high electric breakdown strengths. The two approaches could, however, be constructed to yield more similar elastomers if elastomers from approach 1 are further reinforced or if LR3043/50 is replaced with a softer elastomer. 


\section{CONCLUSIONS}

Two new methods of creating soft silicone dielectric elastomers were developed through the use of chloropropyl-functional silicones. One method was based on chemical cross-linking where chloropropylfunctional copolymers formed the basis of the networks. This approach gave elastomers with a high level of mechanical integrity based on their low viscous losses. Thus, decreases in Young's moduli, caused by the chloropropyl-functional copolymers, did not decrease mechanical stability and thereby the lifetime of the DEs. Furthermore, all elastomers prepared with chloropropyl-functional copolymers were shown to be strainhardening, which is a favourable property for DEs due to the suppression of electromechanical instability. High dielectric permittivities were obtained for films with chloropropyl-functional copolymers (e.g. a $43 \%$ increase), while dielectric losses remained at a very low level. Furthermore, the addition of $\mathrm{TiO}_{2}$ increased the permittivity even further. Electrical breakdown also remained high compared to a pure PDMS reference. The synergistic effect of the low elastic moduli, high dielectric permittivity and high dielectric breakdown strengths thus resulted in a predicted ten-fold improved performance using this approach. The second method was based on the addition of commercially available chloropropyl-functional silicone oil to commercial LSR silicone elastomer. Here the elastomers became increasingly soft with increasing addition of silicone oil to the elastomer. The viscous losses did however also increase with increasing amount of silicone oil. Thereby, the mechanical stability was more compromised using this approach than using the cross-linkable copolymers. The dielectric breakdown strength was found to increase at low amounts of added silicone oil whereas it decreased at larger amounts. The dielectric permittivity increased greatly at high concentrations of silicone oil and reached a two-fold increase compared to the pristine commercial LSR silicone, while the dielectric losses remained at a low level. Overall, the first approach leads to a completely new and improved elastomer matrix which upon further reinforcement could give dielectric silicone elastomers with a better performance than the currently used commercial silicone elastomers. The second approach remains a very useful method for easy improvement of the properties of existing commercial silicone elastomers, where higher dielectric permittivity and softer elastomers are desired.

\section{REFERENCES}

[1] Löwe, C., Zhang, X., and Kovacs, G., "Dielectric elastomers in actuator technology,” Advanced Engineering Materials 7(5), 361-367 (2005).

[2] Brochu, P., and Pei, Q., "Advances in dielectric elastomers for actuators and artificial muscles.," Macromolecular Rapid Communications 31(1), 10-36 (2010).

[3] Madsen, F.B., Dimitrov, I., Daugaard, A.E., Hvilsted, S., and Skov, A.L., "Novel cross-linkers for PDMS networks for controlled and well distributed grafting of functionalities by click chemistry," Polymer Chemistry 4(5), 1700-1707 (2013).

[4] Madsen, F.B., Daugaard, A.E., Hvilsted, S., Benslimane, M.Y., and Skov, A.L., "Dipolar cross-linkers for PDMS networks with enhanced dielectric permittivity and low dielectric loss," Smart Materials and Structures 22(10), 104002 (2013).

[5] Larsen, A.L., Sommer-Larsen, P., and Hassager, O., "How to tune rubber elasticity," Proceedings of SPIE 5385, 108-117 (2004).

[6] Bejenariu, A.G., Yu, L., and Skov, A.L., "Low moduli elastomers with low viscous dissipation," Soft Matter 8(14), 3917-3923 (2012).

[7] Madsen, F.B., Daugaard, a. E., Fleury, C., Hvilsted, S., and Skov, a. L., "Visualisation and characterisation of heterogeneous bimodal PDMS networks," RSC Advances 4(14), 6939 (2014).

[8] Carpi, F., Gallone, G., Galantini, F., and De Rossi, D., "Silicone-Poly(hexylthiophene) Blends as Elastomers with Enhanced Electromechanical Transduction Properties," Advanced Functional Materials 18(2), 235-241 (2008).

[9] Liu, H., Zhang, L., Yang, D., Ning, N., Yu, Y., Yao, L., Yan, B., and Tian, M., “A new kind of electro-active polymer composite composed of silicone elastomer and polyethylene glycol," Journal of Physics D: Applied Physics 45(48), 485303 (2012).

[10] Risse, S., Kussmaul, B., Krüger, H., and Kofod, G., "Synergistic improvement of actuation properties with compatibilized high permittivity filler," Advanced Functional Materials 22(18), 3958-3962 (2012). 
[11] Madsen, F.B., Yu, L., Daugaard, A., Hvilsted, S., and Skov, A.L., "A new soft dielectric silicone elastomer matrix with high mechanical integrity and low losses," RSC Advances 5, 10254-10259 (2015).

[12] Madsen, F.B., Javakhishvili, I., Jensen, R.E., Daugaard, a. E., Hvilsted, S., and Skov, a. L., "Synthesis of telechelic vinyl/allyl functional siloxane copolymers with structural control," Polym. Chem. 5(24), 7054-7061 (2014).

[13] Madsen, F.B., Yu, L., Daugaard, A.E., Hvilsted, S., and Skov, A.L., "Silicone elastomers with high dielectric permittivity and high dielectric breakdown strength based on dipolar copolymers," Polymer 55(24), 6212-6219 (2014).

[14] Larsen, A.L., Sommer-Larsen, P., and Hassager, O., "Some experimental results for the end-linked polydimethylsiloxane network system," e-Polymers 050, 1-18 (2004).

[15] Kofod, G., "The static actuation of dielectric elastomer actuators: how does pre-stretch improve actuation?," Journal of Physics D: Applied Physics 41(21), 215405 (2008).

[16] Pelrine, R.E., Kornbluh, R.D., and Joseph, J.P., "Electrostriction of polymer dielectrics with compliant electrodes as a means of actuation," Sensors and Actuators A: Physical 64(97), 77-85 (1998).

[17] Zhu, J., Stoyanov, H., Kofod, G., and Suo, Z., "Large deformation and electromechanical instability of a dielectric elastomer tube actuator," Journal of Applied Physics 108(7), 074113 (2010).

[18] Zhao, X., and Suo, Z., "Method to analyze electromechanical stability of dielectric elastomers," Applied Physics Letters 91(6), 061921 (2007).

[19] Zhao, X., Hong, W., and Suo, Z., "Electromechanical hysteresis and coexistent states in dielectric elastomers," Physical Review B 76(13), 134113 (2007).

[20] Goswami, K., Galantini, F., Mazurek, P., Daugaard, A.E., Gallone, G., and Skov, A.L., "Reinforced poly(propylene oxide): a very soft and extensible dielectric electroactive polymer," Smart Materials and Structures 22(11), 115011 (2013).

[21] Sommer-Larsen, P., and Larsen, A.L., "Materials for dielectric elastomer actuators," Proceedings of SPIE 5385, 68-77 (2004).

[22] Vudayagiri, S., Zakaria, S., Yu, L., Hassouneh, S.S., Benslimane, M., and Skov, A.L., "High breakdown-strength composites from liquid silicone rubbers," Smart Materials and Structures 23, 105017 (2014).

[23] Yu, L., Vudayagiri, S., Zakaria, S., Benslimane, M.Y., and Skov, A.L., "Filled liquid silicone rubbers: possibilities and challenges," Proceedings of SPIE 9056, 90560S (2014). 